\title{
Study of the Effect of Ability and Motivation Factors on the Failure of Small and Medium-Sized Businesses in Iran
}

Sina Mirzaye ( $\sim$ sinamirzaye@gmail.com )

Islamic Azad University

Reza Aghajan Nashtaei

Azad University, Rasht

\section{Research}

Keywords: business failure, small and medium-sized enterprises, Entrepreneurship Business Strategy, Middle East, Survey Method

Posted Date: February 1st, 2021

DOI: https://doi.org/10.21203/rs.3.rs-156818/v1

License: (c) (i) This work is licensed under a Creative Commons Attribution 4.0 International License. Read Full License 


\section{Abstract}

The effect of small and medium-sized enterprises through entrepreneurship, revenue growth and creation of employment opportunities on the global economy is undeniable. Although these enterprises enjoy some strength like flexibility and compatibility in comparison to larger enterprises, they face a lot of problems which have kept their failure rate high. Therefore, in order to have proper and principled policy and plan to achieve economic development it is important to identify the factors affecting the failure of small businesses.

This study aims to investigate the effect of two individual factors of ability and motivation on the failure of small and medium-sized businesses by studying 30 unsuccessful companies located in Industrial towns of Guilan province by presenting a questionnaire among managers and employees. In this paper, SPSS16 software was used for data analysis and to access the answers of the research questions. According to the results, the impact of sanctions and inflation on motivation was considered as the most significant motivational factor and lack of resources management and being considerate of other's abilities were regarded as the most important ability factors.

\section{Introduction}

Today, the significance of small and medium-sized businesses developed by entrepreneurs in the way of national and regional economic development has been confirmed due to several reasons, including the entrepreneurs' role in creating innovation and sustainable employment and also increasing competitive advantages. Such conditions have lead the macro-policies of countries to support the creation and development of small businesses (Mohammadi Eliasi \& Notash, 2011).

On the other hand, starting a small business is a difficult, frustrating and worrying challenge. The failure rate of such businesses is high, and as a result, they impose high economic, social, psychological, and physical costs on entrepreneurs and other members of society. Starting these businesses requires courage and perseverance. Entrepreneurs must be prepared to deal with torturous problems that can only be overcome with persistence and hard work. Every start-up has its own problems in addition to the usual ones. Every entrepreneur has to open his way through the endless range of problems at the beginning of his work. All these issues and problems can be solved. Those who resist and are not afraid of problems can find their own way (Pakouyan, 2011).

Creating and supporting small and medium-sized enterprises is one of the main priorities in economic development programs in many developed and developing countries. Small and medium enterprises play important roles in creating employment and providing a suitable platform for innovation and increasing exports. Small businesses have more flexibility, entrepreneurship and creativity. These firms can more easily adapt to rapid environmental change and respond more quickly to economic and political factors, attract and employ large sections of the population and trained skilled labor. The provision of specialized manpower for large enterprises is conducted by such enterprises. The complex and rapid developments 
of the last few decades, as well as the acceleration of the process of globalization, have caused various societies to try to prepare themselves for the acceptance of global developments. Until a few decades ago, the establishment and operation of large enterprises used to be considered as an economic advantage and it was argued that the larger the enterprises, the more dynamic and powerful the economy. Although this thinking has flourished over the decades and giant firms have emerged based on it, recent developments especially pressures related to population increase, consecutive innovations, complicated management and decision-making processes, needs for Immediate and necessary decisionmaking and experiences gained from the activities of small and medium enterprises have lightened the importance of these enterprises (Nili \& Dargahi, 2003).

According to this, Audretsch (Aldrich, 1999) states that half of entrepreneurs fail while trying to organize their business. Therefore, identifying the individual causes of these failures is an important issue.

Recent studies by researchers confirm that factors such as lack of ability and enough skills and motivation among managers or entrepreneurs are as the key factors in losing opportunities and the cause for their unwillingness to do an entrepreneurial action and can be influenced by Internal (personal) factors or external (environmental) factors as well as emotional arousals (from past experiences); However, these studies have remained at the theoretical level and have not been studied empirically so far. In general, it can be said that small and medium enterprises continue to live with the aim of finding a repeatable and scalable business model (Charehkhah et al. , 2014). Speed and time are significant factors in the success of a business, but the problem is the rapid failure of these small businesses (Lee OG \& JS, 2016).

This issue becomes more challenging when we know that the individual factors affecting the failure of small and medium enterprises have not been clearly studied and identified yet (Bennett, 2016). The massive volume of failure of small companies as entrepreneurial companies has created the fear of their managers' failure (Cacciotti et al. , 2016). There have been theoretical studies on the impact of individual factors on these entrepreneurial companies' failure and they have not been tested empirically (Lee OG \& JS, 2016 - Bennett, 2016). Recently, based on a comprehensive theoretical study conducted by Cacciotti et al. (Cacciotti et al. , 2016), a theoretical model has been proposed that explains the factors affecting the fear of failure of small and medium enterprises. However, this study has provided only a theoretical model and no empirical study has tested it among companies, yet. Accordingly, considering this study gap with the high growth rate of small and medium enterprises failure, this work was conducted to investigate the individual factors affecting the failure of small and medium enterprises in Iran.

\section{Review Of Literatures}

The term "failure" in Webster's dictionary is defined as "the description or inaccuracy or inadequacy of funds in the short term." Generally, various terms such as company dissolution, organizational death, organizational collapse, bankruptcy and decline are used to describe business failure. An investment fails when a company or organization is unable to attract new capital and financial inflows to the company voluntarily in order to reduce debt, and maintain the financial cycle, and the main reason for this can be 
its management and ownership. There comes an end to what is called bankruptcy, which is stopped due to the judicial and legal stages of the operation.

There is no single definition for business failure in the theoretical literature. In fact, there has not been any general consensus among researchers and theorists on what organizational failure is, how it occurs, and what the consequences are (Ropega, 2011).

Generally, various terms such as company dissolution, organizational death, organizational collapse, bankruptcy and decline are used to describe business failure (Cardozo \& Borchert, 2004).

In the literature, however, some definitions for failure have been proposed by scholars:

- No survival of business for any reason and official announcement of the company (Watson, 2003).

- Ulmer and Nielsen (Ulmer \& Nielsen, 1947) have defined business failure as: accepting failure in order to avoid further costs.

- In this regard, Cochran (Cochran, 1981) also argued that failure of a business could mean the termination of a business to maximize its utilization in a short period of time.

- Freeman et al. (Freeman, 1982) describe organizational death as follows: An organization is dissolved when the usual actions that stabilize its structure, conserve resources, and maintain the loyalty of its members are stopped. A union that bears a license and has a national office, but there is no worker who concludes a contract, no member, and no organizer is a dead union. Similarly, a company that has acquired an organizational identity but has no employees other than its head office staff, is no longer a company.

In Iran, the Ministry of Industries and Mines, Agricultural Jihad and Cooperatives consider small and medium-sized enterprises as industrial and service units with less than 50 employees (Ahmadpour \& Moghimi, 2006). Moreover, according to the studies conducted by Business Research Center and the Small and Medium Industries Development Organization and the current laws in Iran, a group of industrial enterprises with less than 50 employees are among the small and medium enterprises. According to the latest definition of the Small Industries and Industrial Towns Organization, small industries are those that have between 5 and 50 employees and large industries are those that have more than 50 employees.

In a study entitled "Key Factors for Small and Medium Business Failure, A Comparison between the UK and Nigeria", Ihua (Ihua, 2009) compared small and medium business failure factors in the UK and Nigeria. The data of this study were collected through a combination of questionnaire information and semi-structured interviews with 45 industry experts from the two countries. The results showed that poor management in the UK and unfavorable economic conditions and inadequate infrastructure in Nigeria are the key factors in the failure of small and medium-sized businesses.

Ropega (Ropega, 2011) conducted their research on the causes and signs of failure in small and medium enterprises in Poland. The research was funded by the Polish Ministry of Science and Higher 
Education to examine the entrepreneurs' beliefs on the signs and causes of failure of small and mediumsized businesses. Fields suggested in this research as reasons and signs of failure are: quality of management or owner-manager attitude, financial field, marketing and distribution field, human resources, and technology and innovation field. For each designated field, potential causes of business failure have been identified.

Saeedi and Afshari Joo (Saeidi \& Afsharijoo, 2010) in an article entitled "twelve main causes of companies' bankruptcy by reviewing the literature and verifying large and small companies" could categorize the most important reasons for company failure based on their significance. These reasons, based on their importance, include: inefficient management or mismanagement, lack of necessary investment, lack of long-term financing, lack of proper understanding of customer needs, poor marketing and sales techniques, national economic activities, poor cash flow, lack of proper understanding regarding competitors, over-credit development, lack of business knowledge and experience, personnel problems, lack of specialists, and unintended natural disasters.

Arasti (Arasti, 2011) conducted their research under the title of empirical study on the causes of organizational failure in Iran's situation with the aim of identifying the main causes of organizational failure based on empirical study in Iran. The statistical population of their research consisted of 150 owners-managers; out of the questionnaires that they randomly sent to 82 owners-managers, 51 questionnaires were completely filled out. The results of empirical research on owner-manager organizations showed that the most important reasons for the failure are: lack of competent managers, lack of support from banks and financial institutions, insufficient economic scope, and poor government policies. In addition, this study showed that the reasons for failure vary depending on the type of industry and the gender of the manager.

Jim Everett (Everett, 1998) in his study entitled "The Impact of Macroeconomic Factors on Small Business Failure" showed that economic factors are related to the failure of small businesses in a rate of $30 \%$ to $50 \%$. As it was expected, the failure rate was associated with interest rates (where failure was defined as bankruptcy) and unemployment rate (where failure was defined as loss of ownership).

Small businesses can fail for a variety of reasons, but those which are less than 3 years old are more likely to be affected by issues related to finance, demand forecasting, management, marketing, start-up capital, strategy and planning. No matter how solid and strong a business owner's (owners') idea is to start the work, availability of resources, experience, and skills needed to successfully manage and run a business seems critical (Smallbone, 2015).

Arasti et al. (2012) conducted a study entitled "Identifying the impact of individual factors on the failure of newly established Iranian businesses". The statistical population of this research was small start-ups in the industrial sector. They first obtained 4 groups of individual factors including motivation, ability, skill and personality traits by conducting a qualitative study and analyzing 10 semi-structured interviews. Then, by evaluating these factors in the form of a questionnaire in a sample of 158 unsuccessful small companies and analyzing the response of 52 respondents, they concluded that lack of crisis 
management skills and lack of marketing, financial and human resource management skills are the main factors affecting failure of new small businesses in the industrial sector (Arasti et al. , 2012).

Today, the importance of entrepreneurs and small and medium-sized businesses in the development of national and regional economics has been confirmed for several reasons, including the role of entrepreneurs as agents of creating innovation, sustainable employment and also a factor of increasing competitive advantage (Audretsch et al. , 2012). Such a situation causes the macro-policies of countries to support the creation and development of small businesses. On the other hand, small and mediumsized companies, despite having strengths such as flexibility and adaptability, face more problems and difficulties compared to larger companies. These weaknesses need appropriate answers. Research findings show that the failure rate of small and medium-sized businesses in the first 5 years of operation is more than $50 \%$.

In the United States, about $45 \%$ of start-ups last only 8 months, $25 \%$ reach 5 to 6 years, and about $20 \%$ over 10 years.

The results of Freeman (Freeman, 1982) and another study conducted between 1955 and 1975 showed that half of large corporations failed in their first five years, and less than $45 \%$ of organizations formed in 1975 were remained. This indicates that small organizations have a higher degree of decline and failure compared to large organizations (Samuel, 2011). Small organizations have less chance of survival than large organizations. The viability of large organizations stems mainly from the strength of the major participants (such as members, employees, and employers) as well as the volume of their financial assets. In other words, these organizations have the advantage of breadth. Large organizations benefit from higher survival rates due to abundance of resources, public legitimacy, political relations, and economic power. The power of large organizations enables them to absorb real losses better and be more resilient to external threats compared to the smaller organizations. For example, large companies are unlikely to collapse even when they fail.

In Iran, on the one hand, there is a strong need to use the achievements of small and medium-sized businesses, such as entrepreneurship, innovation development and national competitiveness. On the other hand, due to the unfavorable business environment for small and medium-sized businesses to flourish, today we see a high failure rate of existing businesses, especially start-ups, both implicitly and explicitly. In such circumstances, identifying the roots and causes of these failures is critical in order to empower and prepare start-ups, small and medium businesses, for survival and excellence. According to the above-mentioned debates, the following research concerns are raised:

What individual factors affect the failure of small and medium-sized enterprises?

\section{Research Methods}

In order to answer the research question, a study was conducted on managers and employees of inactive (failed) small and medium enterprises located in industrial towns of Guilan province. According to the 
classification of industrial companies in Guilan province, inactive companies are those that operate with a capacity of less than $20 \%$ of their offered capacity; according to the statistics of the Industrial Towns Company of Guilan Province, there are 30 inactive companies in Guilan. In addition, companies with less than 50 employees are considered as small and medium enterprises. The sampling method in selecting the failed small and medium enterprises from the statistical population of the research to answer the questionnaire was full-census and the questionnaire was presented to the whole population. There were two hypotheses and the purpose of the questionnaire was to answer them:

$\mathrm{H1}$ : The failure of small businesses has been influenced by its owners' motivations.

H2: The failure of small businesses has been influenced by its owners' abilities.

These two hypotheses were tested by designing a questionnaire consisting of 14 items that were distributed among 60 people, i.e. a business manager and an internal manager in 30 companies located in industrial towns of Guilan province. In the present study, Cronbach's alpha coefficient was used to measure the reliability of the research, which resulted in $88.1 \%$ for the whole questionnaire. In this study, SPSS software was used to analyze the data obtained from the 60 responses to the research questionnaire. The tests performed are:

1. Friedman test to rank the importance of failure factors

2. Cronbach's alpha coefficient test to determine the reliability of the questionnaire

\section{Results}

In the first part of the statistical analysis, the distribution of statistical samples in terms of variables such as gender, marital status, age, education, relevant work experience and type of industry is examined. The results show that men form the largest part of the statistical population; the majority are also married and in the age range of 40-45 years. Only 6 people did not have a university degree and no one had less than 5 years of relevant work experience (See Table 1 ).

Table 1. Descriptive Statistics of Sample $(n=60)$ 


\begin{tabular}{|c|c|}
\hline Percentage & Personal information \\
\hline & Gender \\
\hline 70 & Male \\
\hline \multirow[t]{2}{*}{30} & female \\
\hline & Age \\
\hline 0 & Less than 25 \\
\hline 30 & $25-30$ \\
\hline 20 & $30-35$ \\
\hline 10 & $35-40$ \\
\hline 30 & $40-45$ \\
\hline 0 & $45-50$ \\
\hline 10 & More than 50 \\
\hline 30 & Marital status \\
\hline \multirow[t]{3}{*}{70} & Single \\
\hline & Married \\
\hline & Academic level \\
\hline 10 & Less than bachelor's degree \\
\hline 80 & Bachelor's degree \\
\hline 10 & Master's degree \\
\hline 0 & PhD \\
\hline \multirow[t]{2}{*}{ Percentage } & Organizational Information \\
\hline & Relevant work experience \\
\hline 0 & Less than 5 year \\
\hline 40 & $5-10$ \\
\hline 50 & $10-15$ \\
\hline 10 & $15-20$ \\
\hline \multirow[t]{2}{*}{0} & More than 20 \\
\hline & Type of Industry \\
\hline 10 & Cellulose \\
\hline 13.3 & Chemical \\
\hline
\end{tabular}




\begin{tabular}{|ll|}
10 & Food Industry \\
30 & Metal \\
20 & Construction \\
16.7 & Electricity \\
\hline
\end{tabular}

In the second part, in order to rank and also compare the average importance of individual factors on the failure of small and medium enterprises, Friedman test was performed. As can be seen from the results of Table 2, with respect to the significant level of 1 , the null hypothesis is accepted. Since the value of ChiSquare with a freedom degree of 1 is zero and the probability value (Asymp. Sig $=1$ ) is greater than the probability of the first type of error $a=0.05$, we vote for the hypothesis approval. This means that there is no significant difference between the two dimensions. Acceptance of the null hypothesis means the dimension of abilities and motivations, is of equal importance to managers and employees.

\section{Table 2. The Result of Freidman test for individual dimensions of failure}

\begin{tabular}{|llll|}
\hline Sig & Degree of freedom & Chi.Square & Number of Samples \\
\hline 1 & 1 & 0 & 60 \\
\hline
\end{tabular}

In the third part, the purpose of conducting Friedman test is to determine and rank the importance of abilities in the failure of companies to identify the most important and least significant factors from the perspective of managers and employees of companies. As can be seen from the results of Table 3 , with respect to the significance level of 0.133 , the null hypothesis is accepted. Since the value of Chi-Square with a degree of freedom of 6 is 9.802 and the probability value (Asymp. Sig $=0.133$ ) is slightly greater than the probability of the first type of error $a=0.05$, we vote for the hypothesis approval. This means that there is no significant difference between the groups. But according to the accepted results from Table 3, lack of resource management, lack of attention to the abilities of others, lack of attention to priorities at work and lack of flexibility in crisis are the most significant factors and not spending enough time on work is the least important abilities in the failure of small and medium enterprises from the perspective of managers and employees of small and medium enterprises.

In the fourth part, the purpose of the Friedman test is to determine and rank the importance of motivation in the failure of companies. As can be seen from the results of Table 3, with respect to the significance level of 0.029 , the null hypothesis is rejected. Since the value of Chi-Square with a degree of freedom of 6 is 14.078 and the probability value (Asymp. Sig $=0.029$ ) is less than the probability of the first type of error $a=0.05$, we reject the hypothesis. This means that at least two groups have significant differences among the groups. According to the accepted results from Table 3, the effect of sanctions on reducing motivation is the most significant factor, and motivation reduction due to the lack of belief in self-efficacy is the least significant factor for the failure of small and medium enterprises. 


\begin{tabular}{|c|c|c|c|c|c|}
\hline $\begin{array}{l}\text { Chi- } \\
\text { square }\end{array}$ & Sig & mean & $\begin{array}{l}\text { Rank } \\
\text { average }\end{array}$ & Factor & $\begin{array}{l}\text { Significance } \\
\text { priority }\end{array}$ \\
\hline \multirow[t]{8}{*}{9.8} & 0.13 & Ability & & & \\
\hline & & 3.5 & 4.7 & Lack of resources management & 1 \\
\hline & & 3.3 & 4.55 & No attention to others' abilities & 2 \\
\hline & & 3.1 & 4.4 & No attention to work priorities & 3 \\
\hline & & 3.4 & 4.35 & No flexibilities in crisis & 4 \\
\hline & & 2.8 & 3.8 & Lack of proper knowledge \& experience & 5 \\
\hline & & 2.7 & 3.5 & Lack of proper education & 6 \\
\hline & & 2.3 & 2.7 & Failure in spending enough time on work & 7 \\
\hline \multirow[t]{8}{*}{14.7} & 0.02 & Motiva & & & \\
\hline & & 3.6 & 5.1 & Effect of sanctions on motivation reduction & 8 \\
\hline & & 3.5 & 5.05 & Effect of inflation on motivation reduction & 9 \\
\hline & & 3.1 & 4.2 & Motivation change during time & 10 \\
\hline & & 3 & 4 & Lack of motivation to continue working & 11 \\
\hline & & 2.9 & 3.85 & Disappointment in business & 12 \\
\hline & & 2.7 & 3.3 & $\begin{array}{l}\text { Other people's Influence on motivation } \\
\text { reduction }\end{array}$ & 13 \\
\hline & & 2 & 2.5 & $\begin{array}{l}\text { Motivation reduction due to lack of belief in } \\
\text { self-efficacy }\end{array}$ & 14 \\
\hline
\end{tabular}

\section{Discussion}

As the results show, the existence of sanctions and inflation are the most significant factors in reducing the motivation and consequently the failure of businesses. The issue of sanctions has made it difficult for companies to access foreign raw materials, and the purchase of raw materials is mostly done through unconventional routes and by intermediaries. Since it is not possible to buy through the banking system, companies have to pay for their purchases through intermediaries and pay more, which actually increases the purchase cost by up to $25 \%$. On the other hand, rising inflation causes a large difference between the rate of return on investment and bank interest rates, which in itself reduces the willingness of investors to invest in industry.

According to the research findings, lack of resource management, lack of attention to the abilities of others, lack of attention to priorities at work and lack of flexibility in crisis are the most important abilities 
in managing small and medium enterprises to prevent their failure. Managers often do not pay enough attention to the organization's resources in their decisions and focus more on the implementation of their future plans. Also, the proper use of the organization's resources by investing part of the resources in order to increase shareholders' profits is not done by managers, which can be attributed to the lack of needed ability to properly manage resources according to the conditions prevailing in the country.

Beliefs such as "most people who are attracted to small and medium enterprises do not have much work experience because most professionals tend to work in large companies" or "inexperienced people leave after receiving the necessary training in small industries", have caused managers who have often been the founders of their companies or have been entrusted with the management of a small group not to participate with employees in their decisions or not to accept their advice; because, firstly, they do not believe in the abilities of their employees, and secondly, they consider gaining experience for employees as an opportunity to leave the company or as a danger to their own position. The successive sanctions imposed on the country and the emergence of inflation and recession over the past decades have made the crisis management ability of Iranian companies more important; the ability that most managers lack and can cause organizations to fail. Making key decisions in critical situations is one of the management knowledge needs for small companies to be able to adapt to structural crises using structural changes considering the small size of their organization and prevent the failure of their organization.

\section{Conclusion}

This study was conducted to identify the impact of two individual factors of ability and motivation on the failure of small and medium enterprises in view of managers and employees of companies that have experienced failure in a sample of 30 in industrial towns of Guilan province. Considering the special role of small and medium enterprises in creating employment and economic growth and helping to create and maintain social stability, and considering their privileged role in increasing exports and creating inventions and innovations and other irreplaceable functions of small and medium industries It seems that one of the best ways to create comprehensive economic and social transformation and development of the country, is the special attention of all policy makers, planners, legislative and executive institutions to the importance and role of these companies. In this regard, the results of the present study can help policy makers and executive agencies by informing them of the reasons for the failure of small and medium-sized enterprises, to take better business process arrangements and provide crisis management training programs and resources. Responsible entities can prevent the failure of this group of enterprises by being aware of the problems of small and medium enterprises and supporting them as much as possible.

According to the research findings, unfavorable economic situations are of the factors that have a great impact on the failure of companies. That is, issues like sanctions and inflation that are beyond the control of industrial units. In such circumstances, managers can only try to overcome these critical situations by improving their crisis management skills and adopting effective strategies and programs. 
One of the most important but overlooked factors by managers is personnel issues. Managers need to take the issue of human capital seriously, put the traditional views aside, and focus on empowering and training their skilled workforce in order to maintain this capable workforce by managing the right human capital for their organization.

Managers should always strive to improve their management skills; so, it is recommended to managers to always keep their knowledge up to date by studying the works written in the field of crisis management and resources, and fix their lack of skills by participating in conferences and discussion groups.

Usually every researcher will face obstacles and limitations in the course of research work. In this research, problems and obstacles can be imagined that one of the limitations of the research is data collection through a questionnaire. The researcher's criterion was to present the questionnaire to all inactive companies, but if the financial data of all inactive companies were available, the selection criterion could be financial indicators.

According to the mentioned research results and the limitations, researchers are suggested in future research to compare the data collected from managers and employees of inactive units with each other to see the views of these people towards each other in terms of individual factors, and to conduct a research similar to the present study, but in a way that only one of the two factors of ability or motivation is considered and try to identify the most significant factor and solutions to solve it.

\section{Abbreviations}

UK: United Kingdom

SME: Small and medium-sized enterprises

SPSS: Statistical Product and Service Solutions

ISIPO: Iran Small Industries and Industrial Parks Organization

\section{Declarations}

\section{Availability of data and materials}

Not applicable

\section{Competing interests}

Not applicable

\section{Funding}

The author(s) received no financial support for the research, authorship, and/or publication 
of this article.

\section{Authors' contributions}

Not applicable

\section{Acknowledgements}

This research would not be possible without the support and cooperation of many people. The author would like to express their appreciation to all the anonymous experts who accepted our invitation to participate in this study and generously dedicated their time and expertise to this project. Also, we wish to thank the administration and staff of Iran Small Industries and Industrial Parks Organization (ISIPO) for their kind assistance and active participation in this research.

\section{References}

Aldrich H. Organizations evolving. Sage; 1999 Oct 19.

Ahmadpour, Mahmoud \& Moghimi, Seyed Mohammad (2006). Fundamentals of Entrepreneurship, publication of Entrepreneurship center of Tehran university.

Arasti, Z. (2011). An empirical study on the causes of business failure in Iranian context. African Journal of Business Management, 5(17): 7488-7498.

Arasti, Z., Zandi, F., \& Talebi, K. (2012). Exploring the effect of individual factors on business failure in Iranian new established small businesses. International Business Research, 5(4), 2-11.

Audretsch, D. B., Keilbach, M. C., \& Lehmann, E. (2006). Entrepreneurship and economic growth: Oxford University Press, USA

Bennett R. Factors contributing to the early failure of small new charity start-ups. Journal of Small Business and Enterprise Development. May 16 2016; 23(2): 333-48.

Cacciotti G, Hayton JC, Mitchell JR, Giazitzoglu A. A reconceptualization of fear of failure in entrepreneurship. Journal of Business Venturing. May 31 2016; 31(3): 302-25.

Cardozo, R., \& Borchert, P. (2004). The Disappearance of Business. [online],available at:http://www.babson.edu/entrep/fer/BABSON2003/II/IIP2

Charehkhah, Chia et. al. "Investing in start-ups; looking at the situation in the country and the region." Tehran: Cultural Institute of Arts, Cultural Convergence and Exchange, 2014. P. 31-40.

Cochran, A. B. (1981). Small business mortality rates: A review of the literature. Journal of Small Business Management, 19(4), 50-59. 
Everett, J. (1998). Small Business Economics 11: 371-390, 1998.

Freeman, J. 1982. “Organizational Life-Cycles and Natural Selection Processes." Research in Organizational Behavior 4:1-32.

Ihua, U. B. (2009). SMEs key failure-factors: a comparison between the United Kingdom and Nigeria. Journal of Social Sciences, 18(3), 199-207

Lee OG, Jeon JS, Na DS. A study on the influence factors on successful small business start-ups-micro credit received from Seoul credit guarantee foundation Indian Journal of Science and Technology. Jun 30 $2016 ; 9(24)$.

Mohammadi Eliasi, Qambar and Notash, Hadi. "Identification of the Roots of Skilled Iranian Entrepreneurs' Failure: A Narrative-Discourse View". Entrepreneurship Development, Fourth Year, Vol. 13 (Summer 2011): p. 31-50

Nili, Masoud and Dargahi, Hassan (2003). "Summary of studies of the country's industrial development strategy plan, Tehran, Sharif University of Technology, Faculty of Management and Economics.

Pakouyan, Hamid Reza, "Study of Entrepreneurship and the Causes and Factors of Fear of Launching a New Business in Iran". 9th National Conference on Entrepreneurship and Management of KnowledgeBased Businesses, January 2011.

Ropega, J. (2011). The reasons and symptoms of failure in SME. International Advances in Economic Research, 17(4), 476-483.).

Saeidi, Hesam \& Afsharijoo,Pouneh(2010)." "twelve main causes of companies' bankruptcy by reviewing the literature and verifying large and small companies".

Samuel, Y. (2011). Organizational pathology: life and death of organizations. Transaction Publishers.

Smallbone, D. (2015). Success and Failure in New Business Start-Ups 2015: 34-47.

Ulmer, M. J., \& Nielsen, A. (1947). Business turn-over and causes of failure.Survey of Current Business, 27(4), 10-16.

Watson, J. (2003). The potential impact of accessing advice on SME failure rates. In 16th Annual Conference of Small Enterprise Association of Australia and New Zealand, Ballarat, Australia.

\section{Figures}




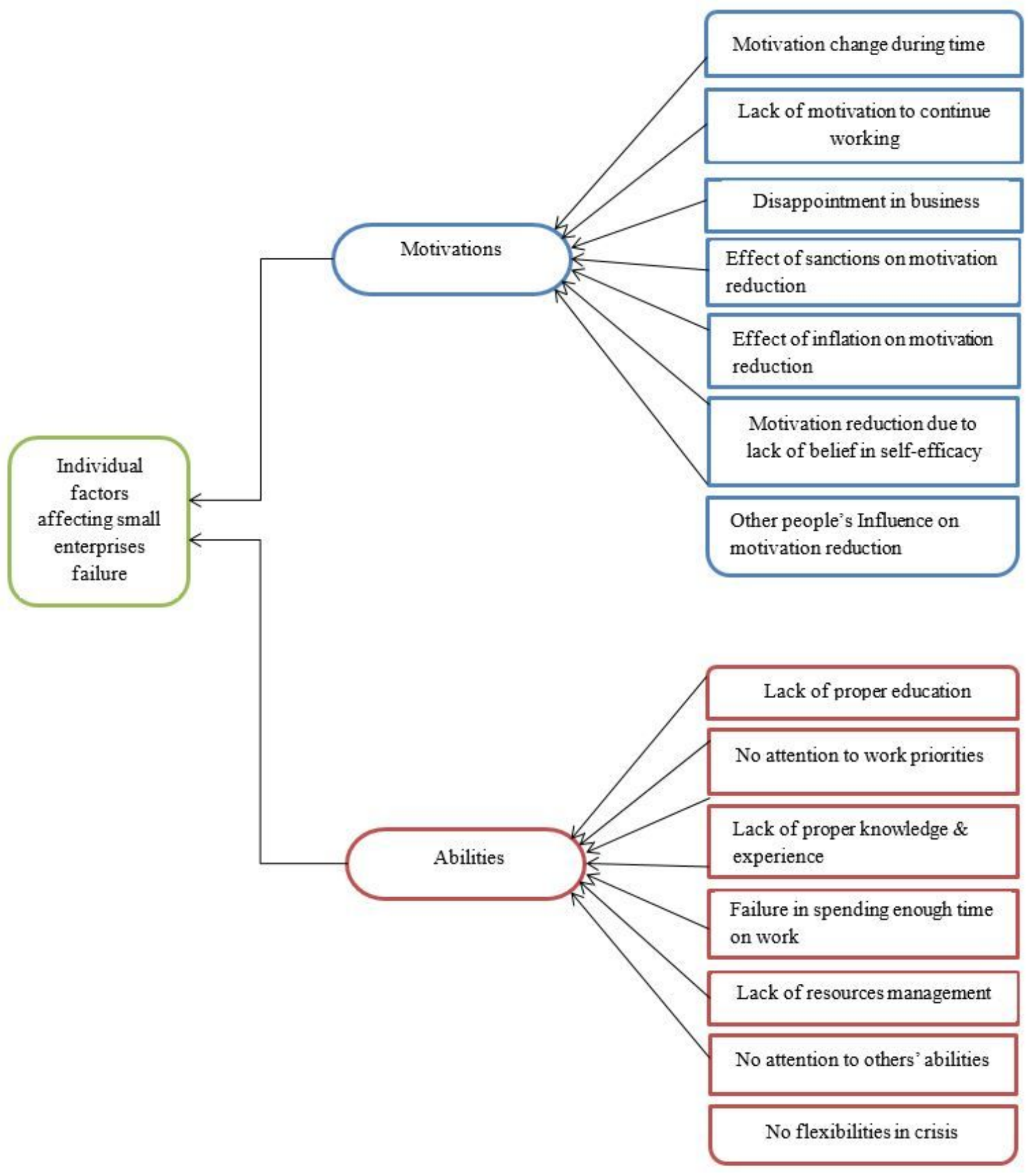

\section{Figure 1}

Individual Factors Affecting Small Enterprises Failure in Iran. 